\title{
Analysis, Design, and Actual Fabrication of a Hybrid Microstrip-SIW Bandpass Filter Based on Cascaded Hardware Integration at X-Band
}

\author{
Kemal Guvenli ${ }^{1,2, *}$, Sibel Yenikaya ${ }^{2}$, Mustafa Secmen ${ }^{3}$ \\ ${ }^{1}$ Department of Electronics and Automation, Hitit University, \\ Kuzey Kampusu, 19030 Corum, Turkey \\ ${ }^{2}$ Department of Electrical and Electronics Engineering, Bursa Uludag University, \\ Gorukle Kampusu, 16059 Nilufer, Bursa, Turkey \\ ${ }^{3}$ Department of Electrical and Electronics Engineering, Yasar University, \\ Universite Cad., No: 37-39, Agacli Yol, 35030, Bornova, Izmir, Turkey \\ kemalguvenli@hitit.edu.tr
}

\begin{abstract}
In this paper, the Microstrip-Substrate Integrated Waveguide (M-SIW) bandpass filter is designed, simulated, and fabricated based on the theoretical analysis. The Substrate Integrated Waveguide (SIW) highpass filter and the microstrip lowpass filter are combined in a hybrid design to achieve the M-SIW bandpass filter in the X-band. This design is more comprehensible and easier to achieve a bandpass filter at a desired frequency. The SIW highpass filter and the microstrip lowpass filter are connected in series to achieve the bandpass filter. To the measured results of the fabricated M-SIW bandpass filter, the center frequency is 10.20 GHz and the bandwidth is $2.40 \mathrm{GHz}$. When the analytical and measurement results are compared, the frequency change in the cut-off frequency is $6.02 \%$ and the frequency change in the bandwidth is $8.74 \%$. It is generally seen that analytical, simulation, and measurement results are compatible with each other. The M-SIW bandpass filter can be broadly used in radar, Worldwide Interoperability for Microwave Access (WiMAX), and satellite technologies. The filters are simulated in Computer Simulation Technology (CST) Studio Suite.
\end{abstract}

Index Terms-Bandpass filter; Cascaded integration; Substrate integrated waveguide; Microstrip.

\section{INTRODUCTION}

Microwave filters play an important role in today's communication technology [1]. Especially in the fifth generation $(5 \mathrm{G})$, wireless communication technologies with high communication speed, microwave filters have a more important place [2]. In addition, satellite technologies are developed rapidly in line with increasing demand. Furthermore, microwave filters have a wide range of applications in satellite [3], Machine-to-Machine (M2M), and radar technologies [4].

Substrate Integrated Waveguide (SIW) has a lower-cost, simple integration, and planar structure compared to rectangular waveguides, but it has a greater loss and lower Q-factor. SIW structures, which act as highpass filters, are used in filter design due to their mentioned properties [5]. Different structures are used to obtain a bandpass filter in some of the previous studies, such as microstrip structure [5], air-filled structure [6], symmetric inductive post structure [7], resonator structure [8], bent structure [9], Low Temperature Co-fired Ceramics (LTCC) structure [10], Through-Silicon Via (TSV) structure [11], cross-coupled structure [12], perturbed circular cavity structure [13], Fourier-varying via-vole walling structure [14], and GaAsbased chip filter structure [15], [16]. As the microstrip structure is easier, cheaper, and more comprehensible, it is preferred for the lowpass filter section of the bandpass filter [17].

The main purpose of this study is to design a modular expandable bandpass filter that can be a reference for future studies. The hybrid bandpass filter is designed in three stages. In the first step, a highpass filter is designed. In the second step, a lowpass filter is designed. In the third step, a substrate integrated waveguide highpass filter and a microstrip lowpass filter are combined in a hybrid filter design. The M-SIW bandpass filter with the desired bandwidth and cut-off frequency is obtained by cascaded hardware integration of these two filter designs. This hybrid design approach helps to produce the bandpass filter transparently and quickly. Simple and clear structures are preferred instead of complex structures. Thus, the bandpass filter with desired cut-off frequency and bandwidth can be designed with fewer variables. This method increases the flexibility of the bandpass filter design.

The lengths of the microstrip lowpass filter parameters are determined based on $0.125 \lambda_{l p f}\left(\lambda_{l p f}\right.$ is the wavelength of the microstrip lowpass filter). The transition from microstrip to SIW is a tapered section [18]. Frequency response of fullmode SIW is better than the transmission efficiency of halfmode SIW. Therefore, full-mode SIW is preferred in this bandpass filter design [19].

\section{ANALYSIS AND DESIGN OF THE PROPOSED M-SIW BANDPASS FILTER}

In this study, the frequency range of the proposed M-SIW bandpass filter is considered $8.39 \mathrm{GHz}-11.02 \mathrm{GHz}$. The 
center frequency $f_{C}$ is $9.62 \mathrm{GHz}$, the $-3 \mathrm{~dB}$ lower cut-off frequency $f_{L}=8.58 \mathrm{GHz}$, the high cut-off frequency $f_{H}=$ 11.2 GHz, and the bandwidth BW $=2.63 \mathrm{GHz}$. The M-SIW bandpass filter is achieved by using a lowpass filter and a highpass filter structures [20], [21]. Firstly, the cut-off frequencies of the lowpass and highpass filters should be determined. In this way, it is possible to get the appropriate bandwidth for a desired cut-off frequency of bandpass filter [20]-[22].

\section{A. First Step: The SIW Highpass Filter Design}

SIW mainly performs as a planar rectangular waveguide. A planar rectangular waveguide is a highpass filter [21], [22].

The geometry and parameters of the SIW highpass filter are shown in Fig. 1. The Rogers $4003 \mathrm{C}$ substrate material is used in filter design $\left(h=1.52 \mathrm{~mm}, \epsilon_{r}=3.38\right.$, and $\tan \delta=$ 0.0027) [20], [23].

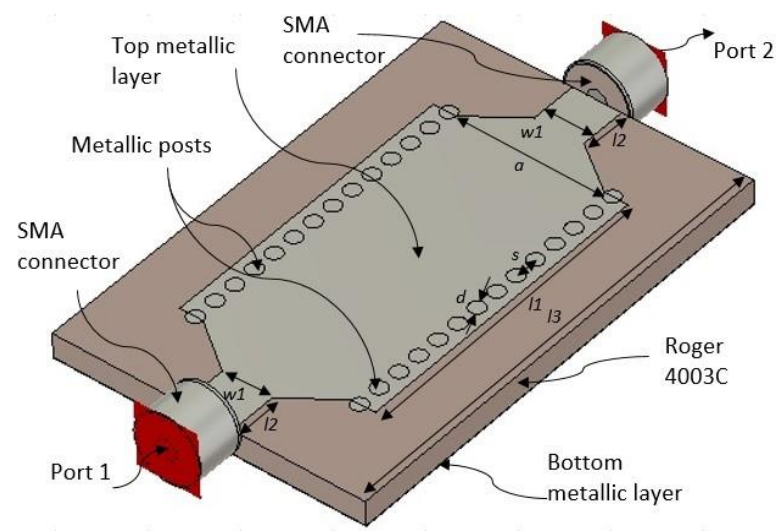

Fig. 1. The geometry of the SIW highpass filter (Top view).

The lengths of parameters of the SIW highpass filter are shown in Table I.

TABLE I. PARAMETERS AND LENGTHS OF THE HIGHPASS SIW FILTER.

\begin{tabular}{|c|c|c|c|}
\hline Parameter & Length & Parameter & Length \\
\hline$d$ & $1 \mathrm{~mm}$ & $l_{1}$ & $19.5 \mathrm{~mm}$ \\
\hline$a$ & $9.5 \mathrm{~mm}$ & $l_{2}$ & $3 \mathrm{~mm}$ \\
\hline$h$ & $1.52 \mathrm{~mm}$ & $l_{3}$ & $30 \mathrm{~mm}$ \\
\hline$s$ & $1.5 \mathrm{~mm}$ & $w_{l}$ & $3.2 \mathrm{~mm}$ \\
\hline
\end{tabular}

The dominant TE mode of a planar rectangular waveguide is $T E_{10}(\mathrm{~m}=1, \mathrm{n}=0)$ mode. The wavelength of the SIW highpass filter $\left(\lambda_{h p f}\right)$ is calculated as $18.983 \mathrm{~mm}$ according to (1), (2). Besides, the CST Studio Suite simulation results of the SIW highpass filter from $6 \mathrm{GHz}$ to $16 \mathrm{GHz}$ are shown in Fig. 2.

$$
\begin{gathered}
f c_{m n}=[1 /(2 \times \pi \times \sqrt{ }(\mu \times \varepsilon))] \times \\
\times\left[((m \times \pi) / a)^{2}+((n \times \pi) / b)^{2}\right]^{1 / 2}, \\
\lambda=c /\left(f \times \sqrt{\varepsilon_{r}}\right) .
\end{gathered}
$$

As shown in Fig. 2, out-of-band frequency suppression is observed to be good in the simulation solution. It is seen that there is a sharp transition-band in the simulation results. The SIW highpass filter has a good "insertion loss" (IL) performance. However, within the frequency band (passband) from $13.5 \mathrm{GHz}$ to $14.5 \mathrm{GHz}$, the "return loss" (RL) performance of the SIW highpass filter is a little poor. The cut-off frequency $f_{C}$ is $8.06 \mathrm{GHz}$ in the simulation results. Based on the simulation results, it is seen that the high pass filter design is good.

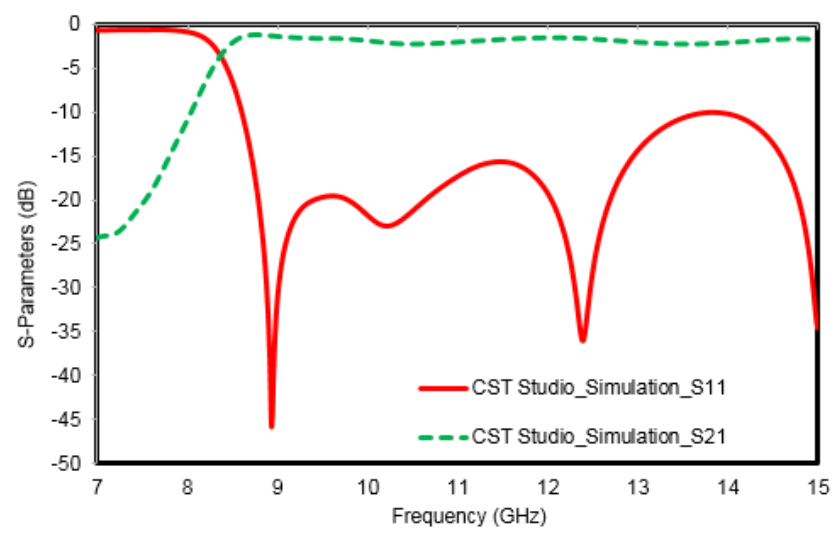

Fig. 2. The simulation results of the SIW highpass filter.

\section{B. Second Step: The Microstrip Lowpass Filter Design}

An easy way to design a microstrip lowpass filter is to use alternative sections that are part of a very high or very low characteristic impedance line. These filters are often described as stepped-impedance because of a good performance of group delay. Therefore, we prefer to use the stepped impedance method to design a microstrip lowpass filter [17], [24]. The Rogers 4003C substrate material is used in filter design.

The geometry and parameters of the microstrip lowpass filter are shown in Fig. 3.

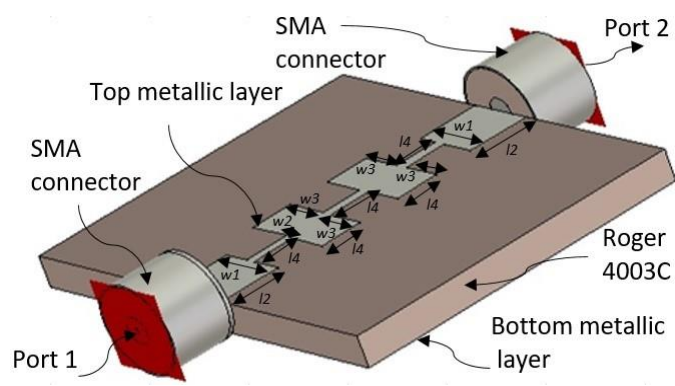

Fig. 3. The geometry of the microstrip lowpass filter (Top view).

The values of the microstrip lowpass filter's parameters are shown in Table II.

TABLE II. PARAMETERS AND LENGTHS OF THE MICROSTRIP LOWPASS FILTER.

\begin{tabular}{|c|c|c|c|}
\hline Parameter & Length & Parameter & Length \\
\hline$w_{1}$ & $3.2 \mathrm{~mm}$ & $l_{2}$ & $3 \mathrm{~mm}$ \\
\hline$w_{2}$ & $0.44 \mathrm{~mm}$ & $l_{3}$ & $30 \mathrm{~mm}$ \\
\hline$w_{3}$ & $1.9 \mathrm{~mm}$ & $l_{4}$ & $1.9 \mathrm{~mm}$ \\
\hline$h$ & $1.52 \mathrm{~mm}$ & & \\
\hline
\end{tabular}

The microstrip lowpass filter is designed by using the Insertion Loss Method. The element values of the equivalent electrical circuit of microstrip lowpass filter are theoretically calculated $\left(\mathrm{R}_{0}=50 \Omega, \mathrm{N}=6\right)$. The circuit elements of the microstrip lowpass filter are $\mathrm{C}_{1}=0.1471 \mathrm{pF}, L_{2}=$ $1.0053 \mathrm{nH}, \quad C_{3}=0.5493 \mathrm{pF}, L_{4}=1.3732 \mathrm{nH}, C_{5}=$ $0.1177 \mathrm{pF}$, and $L_{6}=0.3679 \mathrm{nH}$. The equivalent electrical circuit of the microstrip lowpass filter is shown in Fig. 4(a). The wavelength $\left(\lambda_{l p f}\right)$ of the microstrip lowpass filter is 
calculated as $11.697 \mathrm{~mm}$. Furthermore, the microstrip lowpass filter response between $7 \mathrm{GHz}$ and $15 \mathrm{GHz}$ in CST Studio Suite simulation and analytical results are shown in Fig. 4(b).

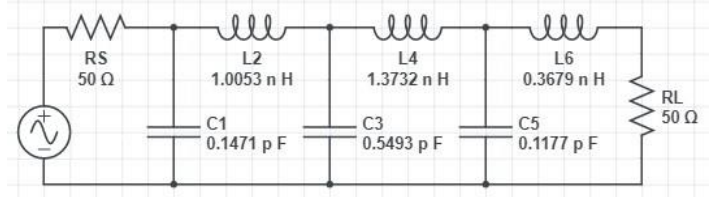

(a)

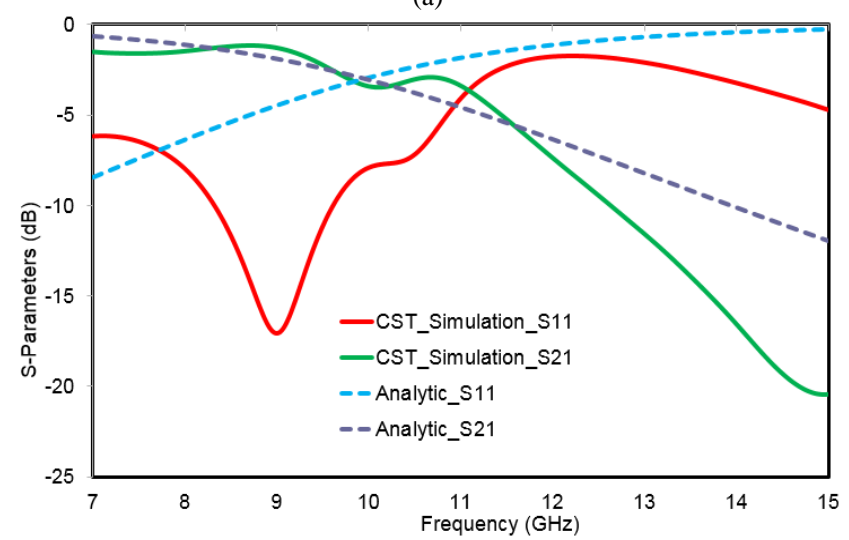

(b)

Fig. 4. The microstrip lowpass filter: a) equivalent electrical circuit (Chebyshev); b) the simulated and analytical results of the microstrip lowpass filter.

As shown in Fig. 4(b), the out-of-band frequency suppression in the simulation is similar to the analytical solution. It is clearly seen that there is a wide transitionband in analytical and simulation solutions. The cut-off frequency, $f_{C}$, is $12.62 \mathrm{GHz}$ in the simulation and $13.94 \mathrm{GHz}$ in the analytic results. Based on theoretical calculations, the frequency change in $f_{C}$ is $7.17 \%$. However, within the frequency band (pass-band) from $7 \mathrm{GHz}$ to $8.5 \mathrm{GHz}$, the "return loss" (RL) performance of the microstrip lowpass filter is a little poor. The microstrip lowpass filter has a good "insertion loss" (IL) performance generally. According to all results, it is seen that the low pass filter design is good.

\section{Third Step: The M-SIW Bandpass Filter Design}

The geometry and parameters of the M-SIW bandpass filter with two ports are shown in Fig. 5.

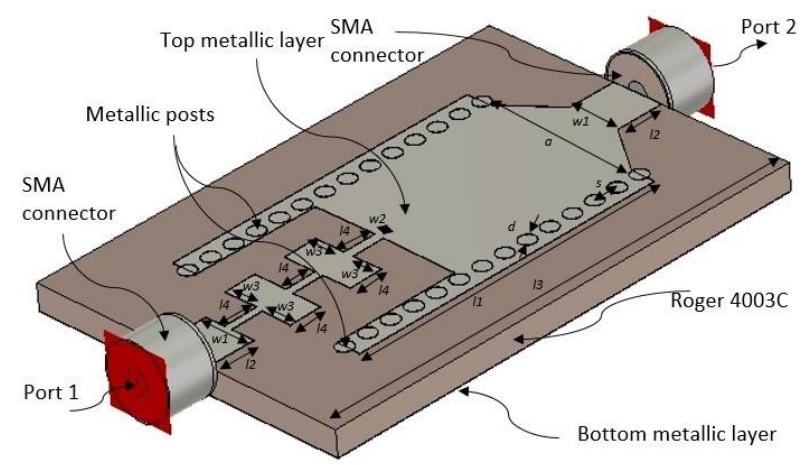

Fig. 5. The geometry of the M-SIW bandpass filter (Top view).

The lengths of parameters of the M-SIW bandpass filter are shown in Table III.
TABLE III. PARAMETERS AND LENGTHS OF THE M-SIW BANDPASS FILTER

\begin{tabular}{|c|c|c|c|}
\hline Parameter & Length & Parameter & Length \\
\hline$a$ & $9.5 \mathrm{~mm}$ & $w_{3}$ & $1.9 \mathrm{~mm}$ \\
\hline$d$ & $1 \mathrm{~mm}$ & $l_{1}$ & $19.5 \mathrm{~mm}$ \\
\hline$h$ & $1.52 \mathrm{~mm}$ & $l_{2}$ & $3 \mathrm{~mm}$ \\
\hline$s$ & $1.5 \mathrm{~mm}$ & $l_{3}$ & $30 \mathrm{~mm}$ \\
\hline$w_{1}$ & $3.2 \mathrm{~mm}$ & $l_{4}$ & $1.9 \mathrm{~mm}$ \\
\hline$w_{2}$ & $0.44 \mathrm{~mm}$ & & \\
\hline
\end{tabular}

The following equations are used for Bandpass Filter Transformations [17]:

- The center frequency, $\omega_{0}$

$$
\omega_{0}=\sqrt{ }\left(\omega_{1} \times \omega_{2}\right) .
$$

- The fractional bandwidth of the pass-band

$$
\Delta=\left(\omega_{2}-\omega_{1}\right) / \omega_{0}
$$

- A series inductor $\left(\mathrm{L}_{\mathrm{k}}\right)$ is converted to $\mathrm{L}_{\mathrm{k}}$ and $\mathrm{C}_{\mathrm{k}}{ }_{\mathrm{k}}$ (Series LC circuit):

$$
\begin{gathered}
\mathrm{L}_{\mathrm{k}}^{\prime}=\mathrm{L}_{\mathrm{k}} /\left(\Delta \omega_{0}\right), \\
\mathrm{C}_{\mathrm{k}}^{\prime}=\Delta /\left(\omega_{0} \times \mathrm{L}_{\mathrm{k}}\right) .
\end{gathered}
$$

- A shunt capacitor $\left(\mathrm{C}_{\mathrm{k}}\right)$ is converted to $\mathrm{L}_{\mathrm{k}}$ and $\mathrm{C}^{\prime}{ }_{\mathrm{k}}$ (Shunt LC circuit):

$$
\begin{gathered}
\mathrm{L}_{\mathrm{k}}^{\prime}=\Delta /\left(\omega_{0} \times \mathrm{C}_{\mathrm{k}}\right), \\
\mathrm{C}_{\mathrm{k}}^{\prime}=\mathrm{C}_{\mathrm{k}} /\left(\Delta \omega_{0}\right) .
\end{gathered}
$$

The Insertion Loss Method is applied in this bandpass filter design. The element values of the equivalent electrical circuit of the bandpass filter are theoretically calculated $(\mathrm{N}$ $=6$ and $\mathrm{R}_{0}=50 \Omega$ ).

The circuit elements of the M-SIW bandpass filter are $C_{l}$ $=0.1678 \mathrm{pF}, L_{1}=1.5732 \mathrm{nH}, C_{2}=1.719 \mathrm{pF}, L_{2}=$ $0.1535 \mathrm{nH}, C_{3}=0.044 \mathrm{pF}, L_{3}=5.871 \mathrm{nH}, C_{4}=2.348 \mathrm{pF}, L_{4}$ $=0.1124 \mathrm{nH}, C_{5}=0.0614 \mathrm{pF}, L_{5}=4.298 \mathrm{nH}, C_{6}=0.629 \mathrm{pF}$, and $L_{6}=0.419 \mathrm{nH}$. The circuit of the M-SIW bandpass filter is shown in Fig. 6.

The wavelength $\left(\lambda_{b p f}\right)$ of the M-SIW bandpass filter is calculated as $11.69 \mathrm{~mm}$ by using (1), (2). The pass-band is $2.63 \mathrm{GHz}$. In addition, the comparison of the analytical and simulation results is given in Fig. 6(b). The value of $\mathrm{BW}$ is $2.63 \mathrm{GHz}$ in the analytical solution, and it is $3.30 \mathrm{GHz}$ in the simulation solution. In general, the out-of-band frequency suppression in the simulation is close to the analytical results. The center frequency, $f_{C}$, is $10.61 \mathrm{GHz}$ in the simulation, and it is $9.62 \mathrm{GHz}$ in the analytical solution.

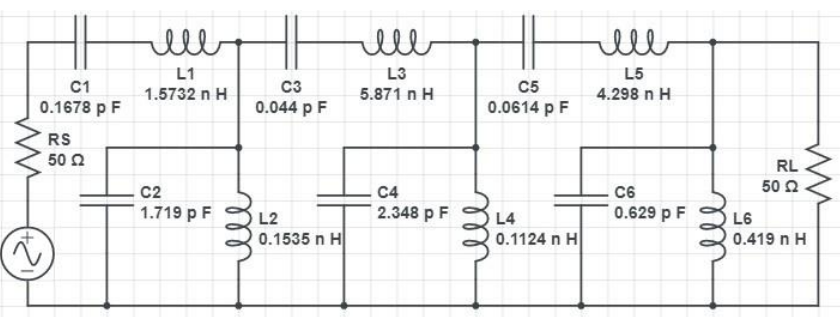

(a) 


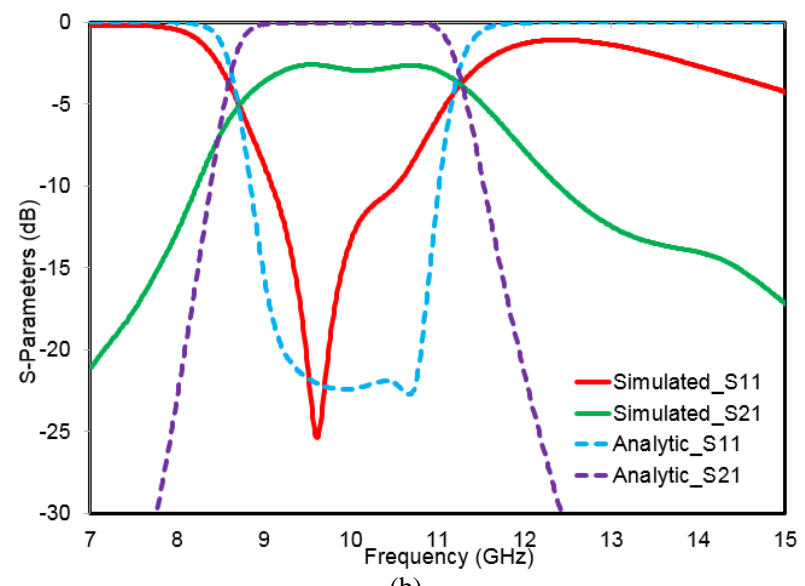

(b)

Fig. 6. The M-SIW bandpass filter: a) equivalent electrical circuit (Chebyshev); b) the simulated and analytical results.

\section{EXPERIMENTAL VERIFICATION AND MEASUREMENT RESULTS}

A Computer Numerical Control (CNC) milling machine is used for filter production. The M-SIW bandpass filter, which is fabricated by using the Rogers $4003 \mathrm{C}$ material, is shown in Fig. 7(a) and Fig. 7(b).

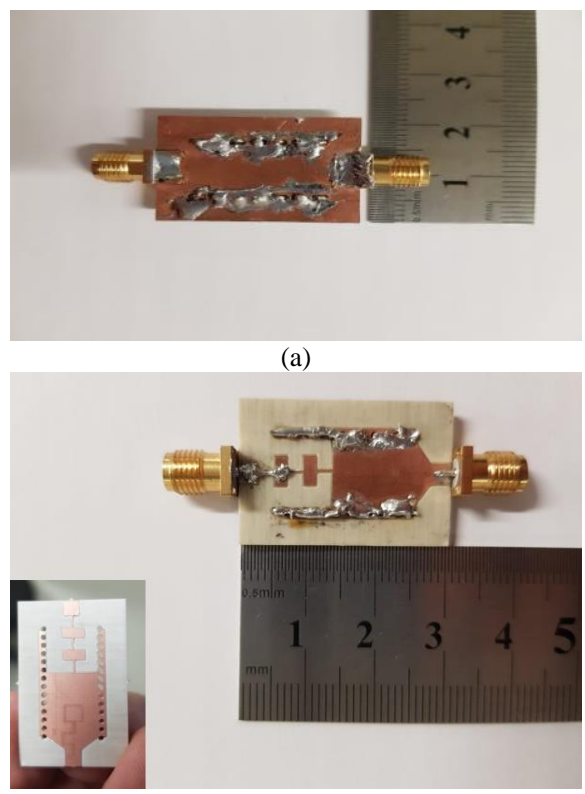

(b)

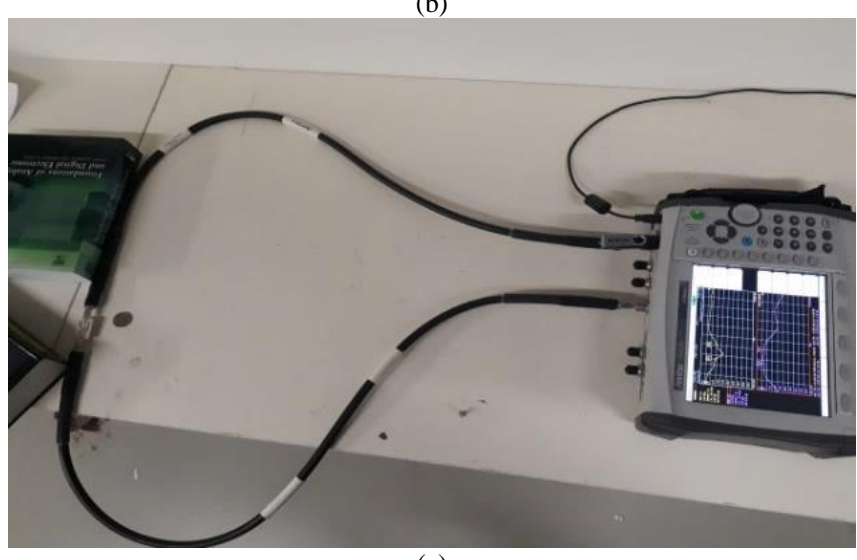

(c)

Fig. 7. The fabricated M-SIW bandpass filter: a) Bottom view; b) Top view; c) the experimental measurement.
The conductive copper wire with a thickness of 1 millimeter is passed through the holes of the SIW filter and it is soldered to the material.

The M-SIW bandpass filter is measured by using the Anritsu handheld vector network analyzer (VNA Master MS2028C) in Antenna and Microwave Lab. of Electrical and Electronic Engineering Dept. at Yasar University. The M-SIW bandpass filter is measured on 4001 points of the frequency range (sampling rate is $10 \mathrm{kHz}$; the whole frequency band is from $7 \mathrm{GHz}$ to $15 \mathrm{GHz}$ ). The M-SIW bandpass filter in the measurement is represented in Fig. 7(c).

The simulated and measured results of the M-SIW bandpass filter are given in Fig. 8. As shown in Fig. 8, the out-of-band frequency suppression in measurement is as good as in simulation. At the same time, the frequency response in the pass-band is close to each other in both simulation and measurement results. The bandwidth in the simulation is $3.30 \mathrm{GHz}$. The center frequency, $f_{C}$, is $10.61 \mathrm{GHz}$ in the simulation.

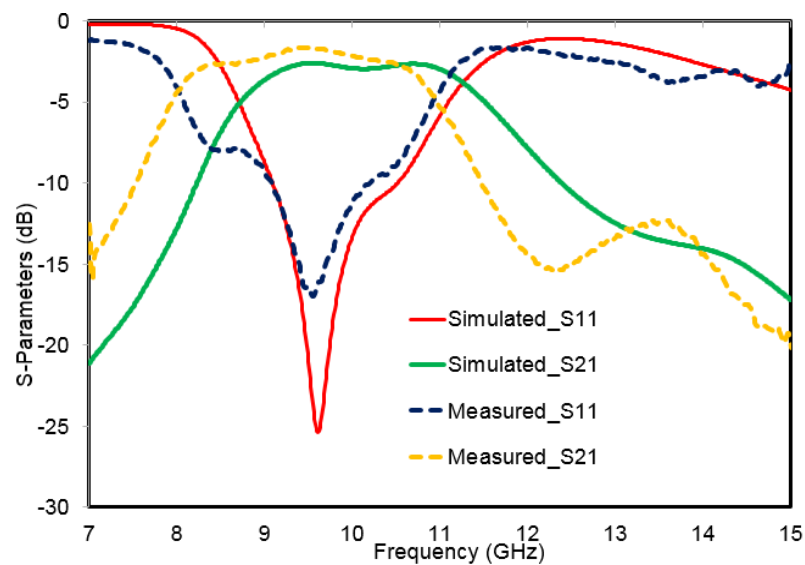

Fig. 8. The simulated and measured results of the M-SIW bandpass filter.

According to the results of the measurement shown in Fig. 8, the bandwidth of the M-SIW bandpass filter is $2.40 \mathrm{GHz}$. The $-3 \mathrm{~dB}$ lower cut-off frequency $\left(f_{L}\right)$ is $9.08 \mathrm{GHz}$, the $-3 \mathrm{~dB}$ upper cut-off frequency $\left(f_{H}\right)$ is $11.48 \mathrm{GHz}$, and the center frequency $\left(f_{C}\right)$ is $10.20 \mathrm{GHz}$. The "return loss" (RL) is commonly greater than $10 \mathrm{~dB}$ in the measured pass-band. In addition, the "insertion loss" (IL) is less than $3 \mathrm{~dB}$ in the measured pass-band.

Analytical, simulated, and measured values are provided in Table IV.

The fabricated bandpass filters with some previous Microstrip-SIW, SIW, Complementary Split Ring Resonators (CSRRs)-SIW, and Spoof Surface Plasmon Polaritons (SSPPs)-SIW are compared with measured performance and type of design in Table V. It is shown that the bandpass filters in [21] and [25] have a very wide passband. The filters in "this work" and [18] have approximately the same "insertion loss" (IL) and "return loss" (RL). The filter in [19] has a very narrow pass-band. However, its "insertion loss" (IL) seems to be the best among them. The filters with different cut-off frequency in "this work" and in [9] have similar BW. 
TABLE IV. THE RESULTS OF ANALYSIS, SIMULATION, AND MEASUREMENT OF THE M-SIW BANDPASS FILTER.

\begin{tabular}{|c|c|c|c|c|}
\hline Operation & $\begin{array}{c}-3 \mathrm{~dB} \text { Lower Cut-off } \\
\text { Frequency }\left(f_{L}\right)(\mathbf{G H z}) \\
\end{array}$ & $\begin{array}{c}\text { Center Frequency }\left(f_{C}\right) \\
(\mathbf{G H z})\end{array}$ & $\begin{array}{c}-3 \mathrm{~dB} \text { Upper Cut-off } \\
\text { Frequency }\left(f_{H}\right)(\mathbf{G H z}) \\
\end{array}$ & Bandwidth (BW) (GHz) \\
\hline Analysis & 8.39 & 9.62 & 11.02 & 2.63 \\
\hline Simulation & 9.09 & 10.61 & 12.39 & 3.30 \\
\hline Measurement & 9.08 & 10.20 & 11.48 & 2.40 \\
\hline
\end{tabular}

TABLE V. THE COMPARISON OF BANDPASS SIW FILTER DESIGNS.

\begin{tabular}{|c|c|c|c|c|c|c|}
\hline Ref. & Type of Design & $\begin{array}{c}\text { Center Freq./BW } \\
(\mathrm{GHz})\end{array}$ & $\mathbf{S}_{\mathbf{1 1}}{ }^{*}(\mathbf{d B})$ & $\mathbf{S}_{\mathbf{2 1}}{ }^{*}(\mathbf{d B})$ & $\mathbf{E r}^{*} / \mathbf{t a n} \boldsymbol{\delta}^{*}$ & Size $(\mathbf{m m} \times \mathbf{m m})$ \\
\hline$[9]$ & Full-mode and CSRR-SIW & $(5.5-8.25)^{* *} / 2.75$ & $>16.5$ & $<2$ & $3.55 / 0.0023$ & $59 \times 17.2$ \\
\hline$[18]$ & $\begin{array}{c}\text { Half-mode and Microstrip- } \\
\text { SIW }\end{array}$ & $12.85 / 9.50$ & $>10$ & $<1.4$ & $2.2 / 0.0013$ & $76 \times 7.1$ \\
\hline$[19]$ & $\begin{array}{c}\text { Half-mode and Microstrip- } \\
\text { SIW }\end{array}$ & $(7.10-7.20)^{* * *} / 0.1$ & $>22$ & $<2$ & $2.2 / 0.0013$ & $123 \times 11.2$ \\
\hline$[21]$ & Full-mode and SIW & $30.83 / 20$ & $>15$ & $<1.5$ & $3 / 0.001$ & $28.8 \times 11.5$ \\
\hline$[25]$ & Half-mode and SSPs-SIW & $(15.6-32.1)^{* *} / 16.5$ & $>10$ & $<0.8$ & $2.65 / 0.0015$ & $80 \times 10$ \\
\hline $\begin{array}{c}\text { This } \\
\text { work }\end{array}$ & $\begin{array}{c}\text { Full-mode and Microstrip- } \\
\text { SIW }\end{array}$ & $10.20 / 2.40$ & $>10$ & $<3$ & $3.38 / 0.0027$ & $30 \times 20$ \\
\hline
\end{tabular}

Notes: ${ }^{*} B W, S_{11}, S_{21}$, tan $\delta$, and $\mathcal{E}$ r mean bandwidth, return loss, insertion loss tangent, and dielectric constant.

**Since the center frequency is not given, the pass-band is written.

\section{DISCUSSION}

According to the hybrid M-SIW bandpass filter results, the center frequency is $9.62 \mathrm{GHz}$ in analysis, $10.61 \mathrm{GHz}$ in simulation, and $10.20 \mathrm{GHz}$ in measurement. The bandwidths of the M-SIW bandpass filter are $2.63 \mathrm{GHz}$, $3.30 \mathrm{GHz}$, and $2.40 \mathrm{GHz}$, respectively.

The result of the S-parameter of the M-SIW filter depends on the diameter of the SIW's embedded metallic post, connector loss, and soldering errors. Therefore, such problems may cause bandwidth deflection according to Table IV. Comparison results between the proposed M-SIW bandpass filter and several manufactured bandpass filters based on SIW are presented in Table V. It is seen that the size of the designed full-mode M-SIW filter $(20 \mathrm{~mm} \times$ $30 \mathrm{~mm}$ ) is smaller compared to SIW filters for X-band applications.

The hybrid design approach (one inside another) is applied to highpass and lowpass filters' structure based on $0.125 \lambda$. This approach is used in the lowpass structure to improve the bandpass filter responses. The measured "return loss" (RL) is generally greater than $10 \mathrm{~dB}$, and the measured "insertion loss" (IL) is less than $3 \mathrm{~dB}$ on the pass-band. The performance of the M-SIW bandpass filter is satisfactory as represented in the RL and IL results. Similar to analytical results, the out-of-band frequency suppression is found to be satisfactory in both measurement and simulation. The simulated bandwidth (BW) of the M-SIW bandpass filter is $3.30 \mathrm{GHz}$ and the measured $\mathrm{BW}$ is $2.40 \mathrm{GHz}$. The reason for the low BW in the measurement results compared to the simulation is thought to be due to the manufacture of the MSIW bandpass filter.

\section{CONCLUSions}

In this study, the theory and hybrid design of the bandpass filter, which has a cascaded structure, are discussed. Unlike the design of the conventional bandpass filter, the M-SIW bandpass filter is clearly presented as a combination of the microstrip lowpass and SIW highpass filters. The period of filter design is shortened and the lowpass/highpass filter effects are clearly seen with this hybrid method. Thus, the bandpass filter can be designed and implemented easily for the desired frequency range. The Rogers $4003 \mathrm{C}$ material is seen to be a proper substrate for the application of the M-SIW bandpass filter. With the Rogers 4003C material, successful results can be obtained in the C-band, as well as in the X-band. However, it is predicted that losses will increase in the Ku-band.

It is concluded that analysis, simulation, and measurement values were found to be consistent with each other. By using this cascaded hardware integration, it is also possible to design new bandpass filters having different cutoff frequency. It is evident that the sensitivity of the CST Studio Suite simulation program based on the Finite Integration Technique (FIT) is satisfactory [26], [27].

\section{CONFLICTS OF INTEREST}

The authors declare that they have no conflicts of interest.

\section{REFERENCES}

[1] L. Huang and N. Yuan, "A compact wideband SIW bandpass filter with wide stopband and high selectivity", Electronics, vol. 8, no. 4, p. 440, 2019. DOI: 10.3390/electronics8040440.

[2] J. Li, Y. Huang, H. Wang, P. Wang, and G. Wen. "38-GHz SIW filter based on the stepped-impedance face-to-face E-shaped DGSs for $5 \mathrm{G}$ application", Microwave and Optical Technology Letters, vol. 61, no. 6, pp. 1500-1504, 2019. DOI: 10.1002/mop.31799.

[3] A. El Mostrach, A. Muller, J.-F. Favennec, B. Potelon, A. Manchec, E. Rius, C. Quendo, Y. Clavet, F. Doukhan, and J. Le Nezet, "An RFMEMS-based digitally tunable SIW filter in X-band for communication satellite applications", Applied Sciences, vol. 9, no. 9, p. 1838, 2019. DOI: 10.3390/app9091838.

[4] A. Kumari, D. Kumar, and A. Kumar, "Dual-band substrate integrated waveguide (SIW) band pass filter for scientific radar applications", International Journal of Information Technology, vol. 11, pp. 875878, 2019. DOI: 10.1007/s41870-017-0076-x.

[5] D. Deslandes and $\mathrm{K}$. Wu, "Integrated microstrip and rectangular waveguide in planar form", IEEE Microwave and Wireless 
Components Letters, vol. 11, no. 2, pp. 68-70, 2001. DOI: $10.1109 / 7260.914305$

[6] I. Mohamed and A. Sebak, "Broadband transition of substrateintegrated waveguide-to-air-filled rectangular waveguide", IEEE Microwave and Wireless Components Letters, vol. 28, no. 11, pp. 966-968, 2018. DOI: 10.1109/LMWC.2018.2871330.

[7] C. T. Bui, P. Lorenz, M. Saglam, W. Kraemer, and R. H. Jansen, "Investigation of symmetry influence in substrate integrated waveguide (SIW) bandpass filters using symmetric inductive posts", in Proc. of the 38th European Microwave Conference, 2008, pp. 492495. DOI: 10.1109/EUMC.2008.4751496.

[8] A. Deleniv and S. Gevorgian, "Design of the compact band-pass filter utilizing dielectric loaded waveguide resonators", in Proc. of 2007 European Microwave Conference, 2007, pp. 886-889. DOI: 10.1109/EUMC.2007.4405335.

[9] S. Moitra and P. S. Bhowmik, "Design and analysis of $150^{\circ}$ bend SIW and corrugated SIW bandpass filter with multiple transmission zeroes using reactive periodic structures suitable for microwave integrated circuits (MICs)", Wireless Personal Communication, vol. 101, no. 1, p. 167-180, 2018. DOI: 10.1007/s11277-018-5681-x.

[10] X. Zhang, J. Yan, H. Zhang, and Y. Chen, "Miniaturized substrate integrated waveguide 5G LTCC bandpass filter exploiting capacitive loaded cavities", Int. J. RF Microw. Comput.-Aided Eng., vol. 29, no. 7, p. e21730, 2019. DOI: 10.1002/mmce.21730.

[11] F. Wang, V. F. Pavlidis, and N. Ju, "Miniaturized SIW bandpass filter based on TSV technology for THz applications", IEEE Transactions on Terahertz Science and Technology, vol. 10, no. 4, pp. 423-426, 2020. DOI: 10.1109/TTHZ.2020.2974091.

[12] A. R. Azad and A. Mohan, "Substrate integrated waveguide crosscoupled bandpass filter with wide-stopband", in Proc. of 2020 URSI Regional Conference on Radio Science (URSI-RCRS), 2020, pp. 1-4. DOI: $10.23919 /$ URSIRCRS49211.2020.9113516.

[13] A. R. Azad and A. Mohan, "Single- and dual-band bandpass filters using a single perturbed SIW circular cavity", IEEE Microwave and Wireless Components Letters, vol. 29, no. 3, pp. 201-203, 2019. DOI: 10.1109/LMWC.2019.2893379.

[14] O. I. Hussein et al., "Substrate integrated waveguide bandpass filtering with Fourier-varying via-hole walling", IEEE Access, vol. 8, pp. 139706-139714, 2020. DOI: 10.1109/ACCESS.2020.3012994.

[15] Y. Xiao, P. Shan, Y. Zhao, H. Sun, and F. Yang, "Design of a W-band GaAs-based SIW chip filter using higher order mode resonances", IEEE Microwave and Wireless Components Letters, vol. 29, no. 2, pp. 104-106, 2019. DOI: 10.1109/LMWC.2018.2890265.

[16] H.-R. Zhu, X.-Y. Ning, Zh.-X. Huang, and X.-L. Wu, "An ultracompact on-chip reconfigurable bandpass filter with semi-lumped topology by using GaAs pHEMT technology", IEEE Access, vol. 8, pp. 31606-31613, 2020. DOI: 10.1109/ACCESS.2020.2972932.
[17] D. M. Pozar, Microwave Engineering. NJ: John Wiley \& Sons Inc. 2012.

[18] F. F. He, K. Wu, and W. Hong, "A wideband bandpass filter by integrating a section of high pass HMSIW with a microstrip lowpass filter", in Proc. of 2008 Global Symposium on Milimeter Waves Nanjing, 2008, pp. 282-284. DOI: 10.1109/GSMM.2008.4534623.

[19] A. Vala and A. Patel, "Half-mode substrate-integrated waveguide based band-pass filter for C band application", Microwave and Optical Technology Letters, vol. 61, no. 6, pp. 1468-1472, 2019. DOI: $10.1002 /$ mop.31837.

[20] A. Jubril and S. D. Nyitamen, " $2 \mathrm{GHz}$ microstrip low pass filter design with open-circuited stub", IOSR Journal of Electronics and Communication Engineering (IOSR-JECE), vol. 13, no. 2, pp. 01-09, 2018. DOI: 10.9790/2834-1302020109.

[21] Sh. Garg and R. K. Raj, "A novel bandpass substrate integrated waveguide filter for the application at $\mathrm{K} \& \mathrm{Ka}$ band", International Journal of Research and Analytical Reviews, vol. 6, no. 1, pp. 10981102, 2019. [Online]. Available: http://www.ijrar.org/papers/IJRAR19J1279.pdf

[22] R. Kumar and Sh. N. Singh, "Compact substrate integrated waveguide multiband band pass filter using octagonal complementary split ring resonators", International Journal of Applied Engineering Research, vol. 12, no. 20, pp. 10127-10133, 2017. [Online]. Available: https://www.ripublication.com/ijaer17/ijaerv12n20_127.pdf

[23] K. Güvenli, S. Yenikaya, and M. Seçmen, "Design and implementation of substrate integrated waveguide filter to work on $\mathrm{X}$ band and Ku-band", in Proc. of 9th International Conference on Ultrawideband and Ultrashort Impulse Signals (UWBUSIS), Odessa, Ukraine, 2018, pp. 198-200. DOI: 10.1109/UWBUSIS.2018.8520006.

[24] Sh. Mitra and D. K. Kumuda, "Stepped impedance microstrip lowpass filter implementation for S-band application", International Journal of Latest Trends in Engineering and Technology, vol. 5, no. 3, pp. 248-255, 2015. [Online]. Available: https://www.ijltet.org/wpcontent/uploads/2015/05/35.pdf

[25] L. Zhao, Y. Li, Zh.-M. Chen, X.-H. Liang, J. Wang, X. Shen, and Q. Zhang, "A band-pass filter based on half-mode substrate integrated waveguide and spoof surface plasmon polaritons", Sci. Rep., vol. 9 , no. 1, 2019. DOI: 10.1038/s41598-019-50056-9.

[26] CST (Computer Simulation Technology) Studio Suite, 2017. [Online]. Available: https://www.cst.com/2017

[27] A. Merfeldas, P. Kuzas, D. Gailius, Z. Nakutis, M. Knyva, A. Valinevicius, D. Andriukaitis, M. Zilys, and D. Navikas, "An Improved Near-field Magnetic Probe Radiation Profile Boundaries Assessment for Optimal Radiated Susceptibility Pre-Mapping", Symmetry, vol. 12, no. 7, p. 1063, Jun. 2020. DOI: $10.3390 /$ sym 12071063 ..

This article is an open access article distributed under the terms and conditions of the Creative Commons Attribution 4.0 (CC BY 4.0) license (http://creativecommons.org/licenses/by/4.0/). 